\title{
The Use Of A Financial Trading Room To Develop Risk Management Competency
}

\author{
R. Ashley Lyman, University of Idaho \\ Robert W. Stone, (Email: rstone@uidaho.edu), University of Idaho
}

\begin{abstract}
The use of a financial trading room and its role in financial trading and risk management education are presented. The program makes use of experiential learning to aid students in the development of competency in financial trading by coupling knowledge with skill. The current status of program features and curriculum are presented first along with anecdotal evidence of its impacts on students. Next the immediate changes planned for the program are presented along with the long term objectives for the program. Conclusions regarding the role of financial trading in providing experiential learning and its impacts on students are presented last.
\end{abstract}

\section{INTRODUCTION}

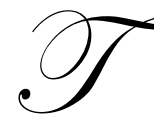

che Association to Advance Collegiate Schools of Business International (AACSB) encourages academic curricula to develop competency among students in a variety areas. These areas include conceptual reasoning, problem-solving skills, and lifelong learning ("Eligibility Procedures and Accreditation Standards for Business Accreditation", 2006). Competency has been defined as the combination of knowledge and skill (Siam, 2005). Competency can also have multiple categories or areas including technical, personal/interpersonal, and industry (Siam, 2005). In the context of business education, the knowledge portion of competency is provided by the discipline specific curriculum in colleges of business. The AACSB suggests that hands-on learning as a way to develop the skills needed to bridge the gap from business knowledge to business competency (Siam, 2005). Hands-on or experiential learning can be accomplished in a variety of ways, even within a single discipline. The purpose of this manuscript is to discuss the use of a financial trading room and risk management as an experiential learning vehicle in financial and economic education.

\section{EXPERIENTIAL LEARNING ACTIVITIES IN BUSINESS EDUCATION}

Different methods to develop skills via hands-on activities have been used in a variety of business disciplines. For example, Hakeen (2001) employed active learning projects requiring students to complete sampling, data analysis, and experimental design to supplement traditional lecture methods. When compared to traditional lecture method alone, these projects were shown to improve student learning (Hakeen, 2001). In a production/operations management environment, an experimental learning factory activity was shown to significantly improve student learning (Polito, Kros, and Watson, 2004). Similarly, a learning activity of developing a marketing plan for the university admissions office by students in a marketing management course has been reported (Washburn and Petroshius, 2004). Another experiential learning activity that simulated managers providing constructive feedback to employees has been reported in the literature (Duhon, Bushardt, and Daniel, 2006). This application had students provide feedback to their instructor on the quality of instruction. The results indicated a reduction in students' cognitive dissonance when providing such feedback and an improved learning atmosphere in the classroom. Finally, in information systems, experiential learning has been introduced through students completing "live" projects for actual clients (Walters and Ritchie, 2006).

A number of experiential learning activities are also reported in the financial education literature. King and Jennings (2004) compared traditional instruction using lectures to these same lectures with the addition of a learning activity requiring students to "paper trade" a portfolio. The results reported that student perceptions of greater learning 
and course satisfaction with the addition of the experiential learning activity, even though the trading produced only paper gains and losses. Similar results were found by Ascioglu and Kugele (2005) when they added an experiential learning activity of an equity trading simulation case to their course. Lekvin (2005) also used a trading simulation in addition to traditional instructional methods and found that student performance improved when using the trading simulation as opposed to the traditional instruction alone. Lekvin (2005) also concluded that the skills developed by students through the trading simulation are skills that are not easily assess by traditional assessment methods. Finally, Norton and Singleton (2005) had students use investment analysis software in addition to traditional instructional methods. They found that students made stronger connections to the lecture concepts when these were reinforced by the use of this software. Furthermore, students generally exceeded the minimum requirements for the exercises when using the software. The authors also noted that the students had developed marketable professional skills in the use of trading software.

Based upon the literature discussed above, it appears that experiential learning activities are used in numerous disciplines, including business. The evidence indicates that these activities generally improve student learning and satisfaction. Additionally, students may also develop marketable job skills. In a broader context, it also appears that such activities help bridge the gap from discipline knowledge to competency. The remainder of the manuscript describes how one university in the intermountain west provides students experiential learning opportunities in economics, finance, and statistics to help bridge the gap from discipline knowledge to competency. The unique aspect of these activities is that rather than students financial trading in only a simulated environment these students actually develop and execute, in conjunction with faculty, financial trades. These trades are analyzed and executed using a financial trading room providing access to real time financial data, analysis tools, and trading software.

\section{THE FINANCIAL TRADING PROGRAM}

In order to increase the relevance of its programs, the College of Business and Economics of this university launched an initiative in the 1990s to develop a curriculum integrating the core business courses (i.e., the "common body of knowledge") by combining and delivering content in economics, business and accounting disciplines in nondiscipline specific courses and modules. The purpose of the core courses and modules was to help students understand the workings of corporations as a whole as opposed to in a functional area. The organization of the content into courses and modules was based on business activities as opposed to functional areas or disciplines. The resulting curriculum was a two semester sequence of courses that students complete as a cohort across two successive semesters. The success of this initiative, particularly in preparing students to be successful in their careers, encouraged the faculty to search for other innovative pedagogical and curricular initiatives. One of these was the establishment in 2002 of a financial trading room within the College of Business \& Economics building.

The trading room was established as a first step in a trading program proposed and personally supported by an alumni of the college who is a successful commodity trader. As the result of his thirty years of experience, he felt that an academic program focused on financial trading and risk management strategies would have wide application in a variety of business disciplines. Furthermore, such a program would fit well with the college's integrated business curriculum and provide unique experiences generating important career opportunities for its graduates.

The resulting Trading and Risk Management Program is built around two principles. First, risk management strategies in financial trading cannot be fully appreciated and understood without experiencing the actual risk to reward relationship found through trading in actual financial markets. Second, the scope of risk management study needs to be sufficiently broad to consider all types of trading strategies for all types of financial instruments or derivatives. As a result, the program allows students to study financial trading in the academic setting but also analyze and recommend actual trading strategies so the risk to reward relationship is experienced first hand.

The design of the trading room has a variety of features. There is a 60 -inch plasma screen configured as a smart board for lectures and presentations. It is also connected to satellite feeds for market and business news and other communication services. The room has seven computer workstations, each with four flat-panel displays. A multiple time zone clock is on the wall. Furniture for interactive student and faculty discussions and conferences is 
also provided. In the fall of 2004, professional trading software from TradeStation Technologies, Inc. was selected and installed on the workstations. Academic waivers for data feeds from the major exchanges were arranged in cooperation with TradeStation and the trading and risk management program formally began.

\section{PROGRAM OBJECTIVES AND FEATURES}

The educational scope of the program is founded on the belief that knowledge about how markets work, firms' market behaviors, and the role of government market intervention are not only important for trading and careers with financial service firms, but can also stimulate students' understanding of economics, finance, and business. For example, successfully trading foreign currency requires knowledge about international trade, monetary policy and the various factors driving international trade and capital flows. When trading equities and options, there is a need to understand accounting statements as well as market structure, demand, and the nature of market competition as well as the type of inter-market relationships that exist.

Functionally, this particular trading program differs from trading programs at other universities in that it does not focus directly on fundamental analysis and equity portfolio management. Instead, it examines trading and risk management strategies applied to equities as well as a variety of financial derivatives such as futures contracts, options, and foreign exchange. A trading fund is used to execute trading and risk management strategies in real market conditions. This fund is managed separately from other university accounts and funds. Its intent is to subject the student traders directly to the risk and reward relationship so critical to understand professional financial trading and risk management. Profits from the fund are applied first to cover the costs of trading and the trading program itself. After covering

The risk to reward relationship and profit sharing features of the program make it unique to business education. This uniqueness provides a source of pedagogical research. The literature on experimental learning does examine, to some degree, the importance of risk to reward relationship. For example, Cooper, Kagel, Lo, and Gu (1999) found that in certain gaming situations, financial incentives impact strategies of play. The literature also discusses the importance of payoffs in producing rational behavior. Smith and Walker (1993) found that when rational decision-making models fail to explain behavior it can usually be traced to unrealistically low opportunity costs that deviate from a realistic decision setting. An interesting research question is whether the presence of the risk to reward relationship alters student and faculty behavior in the market trading of financial derivatives?

Independent of the academic trading room, students in the program are encouraged to experiment in financial trading on their own. In some cases, students personally fund their own, active trading accounts. Anecdotally, the behavior of such students tends to become more intense than prior to trading on their own accounts. A very real explanation for this change in attitude is that students have a deeper understanding of the risk to reward relationship after experiencing it personally. Early in the program, after participating in the trading program, one student worked for a financial services firm over the summer. He spent most of his summer earnings to attend a training seminar of a well know futures and options trader. On the student's return to campus after these experiences, the intensity of his personal trading increased significantly. Furthermore, his enthusiasm infected other students and their intensity and passion for trading increased greatly. All the students involved in the program became more disciplined, precise and focused in their trading and risk management strategies. Based on this anecdotal evidence, direct involvement with the risk to reward relationship appears to have meaningful educational results. In a larger, more general sense, this supports the importance of experiential learning in the educational process.

\section{PROGRAM SIZE, DEVELOPMENT, AND CURRICULUM}

Initially, the trading program was purposely kept small in size. In the first year, three students participated in the trading room and the curriculum. Over the past year, this number was expanded to six and within two years the program will accommodate as many as twelve students. In the future, the program's success and popularity will drive its size. Optimistically, success with trading strategies, education, and faculty research will generate a program large enough to support outside funds from investors. Such funds, managed correctly would be an important revenue stream for the program and College as well as providing tremendous experiential learning experiences for the students. 
A specific objective in the regard to the courses is to develop interdisciplinary relationships and courses among economics, finance, mathematics, statistics, and computer science faculty and areas. Currently, the interdisciplinary nature of the program is to recruit students from the non-business areas. These efforts have been modestly successful. Further cooperation might well lead to an interdisciplinary degree program. At this point in time, the curriculum consists of one course that students complete each semester. The course is informal in the sense that students complete it without credit. Students typically are recruited in their junior year or earlier but are encouraged to participate in the program in their senior year. During their senior year, if they participated in the program in a prior year, students collaborate with faculty in the development and execution of trading strategies. This staggering of students by class assures that in each semester there are experienced student traders as well as new students in the class. Even though students meet in class at regularly schedule times, the students and faculty often meet at other times to study markets and trading positions. This is facilitated by students having access to the trading room on a seven day a week, 24 hours a day basis.

The course content focuses on fundamental analysis, technical analysis, and risk management. The fundamental analysis centers on the forces that influence market changes and the interrelationships among markets. The hope is to use this analysis to understand market trends or non-trends observed within market volatility. Technical analysis is used to validate trends anticipated from the fundamental analysis and attempts to forecast movements in the trend. The hope is to gain favorable price locations within the trend when a trade position is taken. The risk management aspect of the curriculum is to fully understand the magnitude of risk or gain and loss in any trading position and apply techniques to hedge this risk.

Students' background for fundamental analysis is provided by their courses in economics and finance. The curriculum builds upon this background to explain and predict market trends and the interrelationships among markets. The typical student entering the program has little or no experience in technical analysis. For this reason, the required textbook is in technical analysis. The class lectures present technical analysis tools and the application of these tools to market trends identified by fundamental analysis. The risk management content of the curriculum is presented in the context of developing a trading strategy and managing a trade in a manner to fully acknowledge the risk inherent in the trade and to preserve financial capital. This typically involves the use of trading stops and hedging tools as well as adjusting trading positions incrementally to preserve capital in light of changing market conditions. An important supplement to this curriculum is the use of seminars on technical analysis and risk management. These seminars are viewed over the Internet through several of the major exchanges as well as privately purchased DVDs.

The final component to the curriculum is the experiential learning from trading. Based on the class readings, lectures, virtual seminars, and discussions, students are encouraged to develop trading strategies and implement these in a simulated environment. This "paper trading" can be performed in the trading software available in the trading room (i.e., TradeStation). Based on these experiences, the students and faculty discuss potential "live" trading strategies. From these discussions and with faculty approval, actual trades are executed to implement the selected strategies and to manage the associated risks. These trades are discussed and managed as part of regular class meetings.

\section{TRADING PROGRAM CHANGES FOR FALL SEMESTER 2006}

There are several changes scheduled for the trading program beginning in Fall Semester 2006. These changes focus on the academic trading course. The students will enroll and receive academic credit for this course. The course will be a senior-level class receiving three credits and consisting of lecture and laboratory components. In the first semester, the class lectures will cover technical analysis and the laboratory will require students to apply these tools and maintain a laboratory notebook. The laboratory will make use of the "back testing" environment in TradeStation allowing students to develop and evaluate their technical analysis skills. By the end of the first semester of the course, students will be expected to have developed an initial personal trading strategy. During the second semester of the course, students will participate in a trading competition using their personal trading strategies.

The role of the second year or returning students will be three-fold. First, these students will take the lead in developing actual trading strategies and decisions. Second, these students will act as mentors for the first year students 
as they learn to use and apply technical and fundamental analysis tools. Third, these students will complete a financial trading internship during the summer between their first and second year of the program. These internships will be with financial trading firms and the trading program itself to manage the trading account during the summer.

\section{THE LONG TERM DIRECTION OF THE PROGRAM}

There are several long term changes planned for the program. First is the development of significant internship opportunities for students during the summer between their first and second years in the program. The ultimate goal is to have sufficient opportunities to place every qualified student in a true trading internship off-campus each year. A second long term change in the program is to better integrate the trading program curriculum with the other programs in the College. This would require more explicit integration of financial trading content in appropriate courses in the College.

\section{CONCLUDING THOUGHTS}

Based on the experiences in the financial trading program in teaching fundamental and technical analysis as well as risk management, the use of experiential learning adds significantly to the educational process. While a number of academic programs address financial and risk management education, most do not provide an experiential learning component. The programs that do have an experiential learning component provide this component through simulated financial trading. The program appears unique in that it allows students to develop financial and risk management strategies, test them in a simulated environment, but also execute these in the marketplace. While the program is in its infancy, students' perceptions and impacts on their learning encourage further use and development of the program.

\section{REFERENCES}

1. Ascioglu, Asli and Kugele, Lynn Phillips (2005). Using trading simulations to teach market microstructure concepts. Journal of Financial Education, 62(Summer), 69-81.

2. Cooper, David J., John H. Kagel, Wei Lo, and Qing Liang Gu, (1999). Gaming against managers in incentive systems: experimental results with chinese students and chinese managers. American Economic Review, 89(4), 781-804.

3. Duhon, David L., Bushardt, Stephen, and Daniel, Francis (2006). An experiential exercise in giving feedback to enhance student skills. Decision Sciences Journal of Innovative Education, 4(1), 141-146.

4. Eligibility procedures and accreditation standards for business accreditation. (2006). AACSB International.

5. Hakeem, Salih A. (2001). Effect of experiential learning in business statistics. Journal of Education for Business, November/December, 95-98.

6. King, David R. and Jennings, William W. (2004). The impact of augmenting traditional instruction with technology-based experimental exercise. Journal of Financial Education, 61(Summer), 9-24.

7. Lekvin, Brent J. (2005). Some evidence regarding computer-based financial instrument trading simulations and their use as an assessment tool. Journal of Financial Education, 62(Summer), 22-33.

8. Norton, Edgar A. and Singleton, J. Clay (2005). Using professional investment analysis software in the classroom. Advances in Financial Education, Spring, 135-157.

9. Polito, Tony, Kros, John, and Watson, Kevin (2004). Improving operations management concept recollection via the zarco experiential learning activity. Journal of Education for Business, May/June, 283-286.

10. Siam, John J. (2005). University trading centres and their role in business education. Journal of Financial Education, 62(Winter), 1-23.

11. Smith, Vernon L. and James M. Walker (1993). Monetary rewards and decision cost in experimental economics. Economic Inquiry, 31(2), 245-261.

12. Walters, David, Greenwood, Anthony, and Ritchie, Robert (2006). Work-based learning: effectiveness in information systems training and development. Higher Education Quarterly, 60(1), 91-107.

13. Washburn, Judith and Petroshius, Susan M (2004). A collaborative effort at marketing the university: detailing a student-centered approach. Journal of Education for Business, September/October, 35-40. 
$\underline{\text { Notes }}$ 